\title{
Volunteering overseas made easy
}

Previously published at www.cmaj.ca

$\mathrm{W}$ hen disasters strike, such as the recent Haitian earthquake, physicians are among the first to offer their support to aid organizations. Beyond providing disaster relief, many physicians regularly go to areas in need to perform surgery and operate clinics, help organize the health system and offer much needed advice in public health. However, despite a deep-seated desire to help, we and others feel unprepared to meet the many challenges that await a willing volunteer, especially given the many barriers in the current system.

Few would argue about the social good attributed to volunteering overseas. To realize the many benefits of volunteering, motivation is critical. An ideal volunteer is driven by altruism and a real willingness to help others, often at a personal or professional cost.

Volunteers also may derive many direct benefits - such as personal growth, satisfaction and reward - that ultimately result in positive influences for their patients and institutions at home. One might learn about other cultures, come to appreciate better public health and social needs in different contexts, and potentially recognize a broader range of solutions to problems back home. Many come to realize that there are no simple solutions to many big problems in poor resource settings.

Volunteering, especially in conflict zones or disaster relief settings, may also have serious negative effects. Without proper training, volunteers may be more of a burden than a help. They may be asked to provide services for which they are ill-equipped that may jeopardize the health of their patients. They may impose approaches to care that are culturally insensitive or outright inappropriate. Or they may simply be in the way of professionals who are trained to help in these settings.

Even well-trained and effective volunteers are at risk of personal negative experiences - such as witnessing the consequences of extreme depravity, violence and brutality, or social injustices - that can leave emotional scars that may even lead to post-traumatic stress disorder.' Personal relationships with families or work may suffer if volunteer activities are extended for long periods.

The many challenges should not dissuade us from doing more. With better support and fewer impediments, perhaps more of us would volunteer abroad. Already, about $30 \%$ of us volunteer some of our time, one-third of that in our role as physicians. ${ }^{2}$ Many young physicians, even those still in training, as well as more senior physicians who are contemplating retirement or are recently retired want to do more. However, when asked, they highlight many barriers, including a lack of coordination, limited organizational support and personal unpreparedness. ${ }^{3.4}$

Many questions arise. What support services should be offered and by whom? How do we match the volunteers' skills with the needs abroad? How should volunteers prepare for travel and their own health needs? What about health insurance and malpractice coverage? Who will cover their clinical duties during their absence?

Answers are, in large part, dictated by the importance and priority we attributed to volunteer activities. Some funding and investments are required to overcome existing barriers. Ongoing coordination of volunteer activities by an association or society might better assess overseas needs and help match important gaps with available skills. Supporting a network where returning volunteers can share experiences with each other and newcomers might diminish some of the impact of volunteering and help promote programs. Specialty societies could develop and offer more discipline-specific educational programs as well as opportunities. The American College of Surgeons has demonstrated outstanding innovation and leadership in this regard.

Local support, at least in faculties of medicine, may be offered by international health offices. Faculties of medicine and health sciences need to find ways to recognize volunteerism as a legitimate, praiseworthy and promotion-eligible activity for all faculty and trainees. Similarly, at the regional and national levels, volunteer activities should be recognized and credited by the Royal College of Physicians and Surgeons of Canada and the College of Family Physicians of Canada to maintain certification requirements. Clearly, similar programs should be considered for other health disciplines.

Our hospitals, clinical partners and other colleagues need to learn to support departing volunteers, primarily by arranging to fill the void in clinical, administrative and academic services with the promise of a warmth welcome on their return.

We should praise our colleagues who volunteer, to be sure. But we also need to break down barriers, coordinate opportunities and actively support effective volunteer initiatives. Then perhaps more of us will be ready to go where needed, when needed.

\section{Ken Flegel MDCM MSc \\ Senior Associate Editor \\ Noni MacDonald MD MSc \\ Section Editor, Public Health \\ Paul C. Hébert MD MHSc \\ Editor-in-Chief \\ CMAJ}

With editorial advisory team member,

Matthew B. Stanbrook MD PhD

Competing interests: See www.cmaj.ca/misc/edboard.shtml

CMAJ 2010. DOI:10.1503/cmaj.100734

\section{REFERENCES}

1. Hagh-Shenas H, Goodarzi MA, Dehbozorgi G. Psychological consequences of the Bam earthquake on professional and nonprofessional helpers. J Trauma Stress 2005; 18:477-83

2. 2007 National Physician Survey. Mississauga (ON): National Physician Survey; 2007. Available: www.www.nationalphysiciansurvey.ca/nps/2007_Survey /2007results-e.asp (accessed 2010 May 27).

3. Hayanga AJ. Volunteerism in residency: pride and prejudice. J Am Coll Surg 2010; 210:253.

4. Shephard EM, Klein EJ, Koelemay KG. Disaster preparedness: Are retired physicians willing to help? Am J Disaster Med 2009;4:279-86.

5. Operation giving back. Chicago (IL): American College of Surgeons. Available: www.operationgivingback.facs.org/ (accessed 2010 May 27). 